\title{
Insurance of risks as the instrument of protection of investments into high-rise construction
}

\author{
Elena Vasilyeva ${ }^{1, *}$ and Vladimir Okrepilov ${ }^{2}$ \\ ${ }^{1}$ Moscow State University of Civil Engineering, 129337, Yaroslavskoe shosse, 26, Moscow, Russian \\ Federation \\ ${ }^{2}$ Federal State Budgetary Institution of Science Institute of Regional Economic Problems of the \\ Russian Academy of Sciences, 190003, Serpuhovskaya st.,38, St. Petersburg, Russia
}

\begin{abstract}
Insurance now is one of the important sectors for both world, and national financial systems. The mechanism of insurance of risks plays an essential role in the process of construction of high-rise buildings and as well as other unique objects. The author argues that insurance is categorically necessary because of the following reasons: huge scale and complexity of high-rise projects and great expenses, the use of unsafe sites for construction, great possible losses in case of the project, important role for the city infrastructure, numerous organizations, involved into the process of construction and maintenance, multypurpose use of the building. The features of insurance in the field of high-rise construction is also considered in the article. The prerequisites, confirming the loss occurrence are named.
\end{abstract}

\section{Introduction}

Construction industry as whole and high-rise construction particularly is subject to more risk and uncertainty than many other industries.

The development of a high-rise construction project from inception to completion takes a long time and involves many phases. It brings workers with different skills and interests together and involves the use of large and diverse set of equipments. All of these complex requirements have to be handled with proper co-ordination to provide a smooth flow of activities. It is necessary to identify and analyse the risks that may appear during project risks means the control of the project itself .Insurance is, of course, only one means of managing risks associated with such projects. It needs to be put into context and understood that not every risk can be insured against adequately or insured for a price that is acceptable [1].

Speaking about insurance of high-rise buildings, we have to consider first of all the whole complex of various self-contained types of insurance created in last years which are bound to the construction and maintenance of such objects. Besides, it is necessary to think about

\footnotetext{
*Corresponding author: elena.chibisova_metr@mail.ru
} 
the features and padding risks distinguishing insurance of high-rise buildings upon insurance of other constructions.

The article aims in conducting an investigation on how insurance is used as a risk transfer tool in the construction industry and examine the interaction between construction players and insurance companies with respect to risk management. The attempt to present interaction of main types of insurance of structural risks, their temporary sequence and transitions between them is also made in the article.

\section{Methods}

How insurance of investments into construction of high-rise buildings is carried out? In the figure 1 the main steps which need to be undertaken are shown [2].
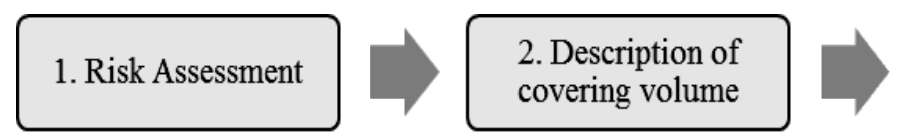

\section{Insurance realization}

Fig. 1. Stages of insurance of investments into high-rise construction.

1. Risk assessment is the first stage. On its basis the insurer has to define whether he or she is ready to insure this risk in a way desirable to the client. And, besides, on the basis of risk assessment the insurer decides in what volume he intends to participate in him. Assessment of risk is carried out on the basis of definition of the insured sum and the level of insurance premiums which is based on her. Quite often during construction of the building the cost of construction works considerably increases: wrong assessment, the arisen difficulties, inflation, etc. can be the reasons. It is recommended to keep track constantly of dynamics of expenses and in due time to coordinate the correcting measures with the insurer.

Also it is recommended to coordinate a higher insured sum, an extra charge to an award, in order to avoid a possible underinsurance at the stage of signing of the contract. Upon the termination of insurance term the difference comes back to awards to the insurer.

2. Along with the definition of the insured sum the description of volume of a covering is formed. Types of coverings are concretized in reservations of the contract, certain risks are excluded. As for high-rise projects, that can be:

- special conditions of fire safety on building sites;

- special conditions at a construction of the base of deep laying;

- responsibility to the third parties - vibration, removal or weakening of the bearing elements;

- special conditions of laying of underground cable lines, pipelines and him similar constructions.

These provisions are in writing fixed in the policy.

3. The third step is the insurance realization. Insurers are partners of the insurer here. However they also are economically interested in fast, effective implementation of the project properly. For this purpose they conduct examination of the building site [3, 4].

The insurer first of all is interested in the following aspects $[5,6]$ :

- management, control;

- the updated job schedule;

- work flow;

- storage conditions of materials;

- measures of fire safety;

- administrative work;

- special conditions on a building site;

- unprofitability; 
- construction documentation (photo of the site);

- recommendations about improvement of the organization of construction and security measures;

- control of dates of performance, results;

- the plan of measures on prevention of damage from a storm or a flood.

\section{Results}

The need and economic validity of insurance of installation and construction works and also the subsequent insurance of property of buildings are so not obvious anywhere, as in the field of a construction and operation of high-rise objects. For this purpose there are several reasons:

1. High-rise projects represented and represent huge investment projects. Costs of construction at the level of 1 billion US dollars presently is not a rarity any more.

In most cases these means will be mobilized by means of the credits. The investor, naturally, wants to insure himself from technical, natural and human risks which can threaten his investments into construction time [7].

Decrease in risks allows to reduce the cost of the credits.

2. High-rise buildings play an important role in city infrastructure. As a rule, they are built in the center of the large cities and influence other elements of infrastructure. It assumes exact observance of the provided terms of carrying out construction works, etc.

3. Modern high-rise objects become more and more complex systems. Hundreds of the organizations are often involved in their construction.

4. Modern high-rise buildings are often intended for complex use: individual housing, restaurants, hotels, offices and administration premises, halls for holding various actions, the movie theaters, theaters, parkings, etc. belonging to various operating organizations getting or renting parts of the building.

5. Quite often they are constructed in territories where natural cataclysms are possible: in deserts, seismo-dangerous zones, on unsafe sites of the coast, in the sea, etc. They are under construction in areas with unreliable soil and in zones of storm influence.

6. Their construction is quite often conducted on a limit of technical capabilities of the time.

7. Modern high-rise objects (and not only they) represent today not so much buildings how many some kind of "machine for accommodation". That increases the importance of the machinery and equipment, and respectively, and insurance of technical risks.

What contents and features of insurance of construction risks of high-rise objects?

If to one looks at property insurance in a chronological order, then it is necessary to begin with insurance of construction risks which actually begins with with delivery of the first construction materials and the equipment. And it comes to the end with the termination of a construction of an object and its transfer to operation.

The purpose of insurance is in protecting construction (it can be both capital repairs, and reconstruction of the building, and installation of constructions and the equipment) from all usually expected technical and natural risks, to provide to the contractor or to the customer an opportunity to eliminate with the fastest image the arisen damage to avoid more long breaks in production and idle times which can arise for the called reasons.

Insurance of construction risks for high-rise buildings should be carried out as CAR insurance (Construction All Risks - all construction risks) within technical insurance. It covers the risks threatening construction of the building or installation of equipment. Insurance "from all risks" means that all risks, except specified in Exceptions are insured. Risks of the fire, explosion, destruction or collapse of parts of already built design and also, 
as a rule, natural disasters, such as earthquakes, storms, floods, etc. and also thefts of construction materials and the construction equipment, etc. become covered.

Perhaps also combined design insurance of the high-rise building (Comprehensive Project Insurance) includes all basic elements today. Such policy represents individual option (tailor made) corresponding to uniqueness of the majority of high-rise buildings.

If we consider a complex of the corresponding types of insurance in an approximate chronological order, then at the beginning of a chain there is an insurance of responsibility of architects, designers and engineers which subject is civil responsibility. This type of insurance allows to cover risk of emergence of damage to the third parties at design and construction which results from mistakes or omissions of architects or design engineers .

$\mathrm{He}$ is followed by the insurance of the construction risks (CR) which is carried out by us in the form of "all construction risks" and "all assembly risks". At the same time it is about a covering on the basis of insurance "from all risks".

This type of insurance uses terms checked in the policy (named perils insurance insurance of the named risks). It allows to indemnify the material damage which has arisen during operation of the building and can carry the name "insurance of operational risks" (operational cover) also [8].

In parallel the operating organization (organizations) or various users of an object quite often sign contracts of insurance of civil liability before the third parties in connection with damage which they can incur as a result of operation of this building.

All above-named phases of implementation of the project can be followed by insurance of losses from a delay of the beginning of production activity (e.g., in case of failure to deliver for rent because of untimely commissioning), has arisen as the instrument of protection of investments for a covering of material damage which can arise in the course of a construction of an object and installation of equipment. In most cases as the insurer here as a rule the contractor (contractor) in coordination with the customer (principal) acts.

Before construction and during a construction of a high-rise object on the building site materials and quite often very expensive structural elements of the building, the equipment have to be delivered.

At this stage in process of the growing volume and cost of the transported elements the expediency and importance of signing of the contract of transport insurance increases. These risks can be included also in the form of additional reservations in the contract of insurance of SMR.

In parallel, and it is frequent within the insurance program, integrated with CAR, the contract of insurance of responsibility of civil engineering firm which protects the insurer (the customer, the contractor, subcontractor, etc.) from risks of presentation of the financial requirements following from civil liability for the loss caused to the third parties in the course of construction of this object is signed. The civil liability of civil engineering firms gains the growing value especially when the part of the building even in the course of construction is put into operation.

Now trade and the congress centers quite often begin to function on first floors of the building before completion of construction of the building that can cause the necessity of insurance of electronic devices [9].

There is also a number of special insurance policies which can be acquired depending on purpose of the building, etc.

Here it is possible to carry also types of personal insurance, such as insurance of civil liability of the employer.

The decision on what types of insurance to choose to the owner operating the organizations, to the customer of construction works, the contractor, the architect (each party having insurance interest) are accepted first of all by the customer and the contractor in common with the insurer on the basis of the project documentation. She contains technical 
parameters of the ready high-rise building, a basis of his integration into the existing platform infrastructure.

It, naturally, increases the cost of the policy of assurance of civil liability.

A few years ago the Munich reinsurance society has put into operation more modern insurance, combined in many sections of projects, called - Comprehensive Project Insurance (CPI). It contains up to four sections and can include all above-stated segments (insurance of transport, construction-and-installation works, construction equipment and civil liability) which can be also combined with insurance of losses from the delays of the beginning of a production activity which have resulted from suspension of installation and construction works or supplies of equipment as a result of problems with transport.

After transfer of an object to the owner or the operating organization the insurance described above is succeeded by annual renewable property insurance. The builder, the owner or the operating organization (operator) becomes the insurer now.

This insurance includes compensation of material damage and some other types of a covering.

The most important of all types of insurance of high-rise buildings, undoubtedly, is insurance upon the fire. It is caused by assessment of scale of possible losses, or PML (Probable Maximum Loss - the greatest possible loss). The speech in this case goes about insurance of property which covers the risks stipulated in the policy.

\section{Discussion}

Sceptics can object that receiving compensation from insurance company - a difficult procedure and that the company can have occasions to refuse to the insured person payment. To disprove these fears, it is necessary to discuss in what case payments for insurance are carried out?

Really, the refusal of compensation payment in principle is possible. But two prerequisites which existence authentically confirms the loss occurrence are always important and guarantees compensation payment:

1) There has to be a sudden, unforeseen event, which came irrespective of the insurer and the insurer and led to a loss.

2) An object to which damage is caused has to be insured from risks, i.e., insurance validity has to extend to it.

Besides, it is necessary to learn precisely who in a concrete case is an insurer as cases when they mistakenly address not to that firm are frequent.

The question is subject to examination whether there was a loss, for example, in the course of construction and whether he has been caused by one of the hidden dangers or it is about a loss, responsibility for which is born by the third organization $[10,11]$.

Reinsurance plays important role in insurance of installation and construction works.

In effect overcautious persons are insurers of insurers. They make available to insurers financial means for a covering of large risks.

From the aforesaid becomes clear that reinsurance has to play especially important role in insurance of installation and construction works on high-rise buildings. It is caused by the following factors [12]:

- The considerable sums and limits of insurance which follow from high investment expenses and the greatest possible loss.

- Danger of accumulation of losses on different types and categories of insurance (for example, installation and construction works, responsibility of builders, personal insurance).

- Accumulation of risks turns out and as a result skyscrapers for infrastructure and townplanning reasons are quite often built at small distance from each other. As it was already 
mentioned above, they are structurally connected to other buildings and infrastructure facilities or are under construction in close proximity to them.

- Now skyscrapers are built in the areas subject to natural risks: to storms, earthquakes, tsunami, etc.

\section{Conclusion}

It is possible to prove that if there is no insurance and effective work of the insurance companies, the majority of high-rise objects would not be under construction today, they were not under maintenance and were not on sale.

Large investment projects on construction of high-rise buildings can turn back in case of failure huge risks for the investor. That itself proves need of fears,

It is clear, that insurance in the sphere high-rise constructions has the features. Large investment projects on construction of high-rise buildings in most cases are unique, sometimes not having analogs at the national level. Insurance companies have to accumulate the international experience of a construction of similar objects. They have to have qualified personnel that will give them the chance to give support to clients in assessment of risks, underwriting, formation of insurance programs and in settlement of losses.

It is important that insurers chose financially steady insurance companies having the sufficient capital which in case of damage could pay the share on a loss. As each insurer can and has to assume only a certain share of risk (from the insured sum or limits), one or several overcautious persons are necessary for him. Re-insurers also have to limit the responsibility.

\section{References}

1. A. Babu, S. Kanchana, International Journal of Civil Engineering and Technology, 5 12, 206-210 (2014)

2. A. O'Sallivan, City economy (Moscow, INFRAM, 2002)

3. N. Bunni, Risk and insurance in construction (Spon, London, 2003)

4. D. Heidenhain, Geneva Papers on Risk and Insurance - Issues and Practice, 26(2), 268276 (2001)

5. M. Rahman, M. Kumaraswamy, Engineering, Construction and Architectural Management, 9 (2), 131-151 (2002)

6. E. Rendell, D. Yablonsky, Risk manager's insurance guide (Department of Community and Economic Development, Harrisburg, 2003)

7. V.P. Generalov, Features of design of high-rise buildings Samara (Samara State architecture-and-construction University, 2009)

8. W. Leontief, The Structure of the American Economy, 1919-1929 (Cambridge: Harvard University Press, 1941), https://doi.org/10.1017/S0022050700053158 Published online: 01 February 2011

9. J. Pridmore, Chicago Architecture and Design (New York: Harry N. Abrams, Inc., 2005)

10. A. Mottaeva, MATEC Web of Conferences, 73, 07020 (2016)

11. A. Mottaeva, IOP (Earth and Environmental Science), 90, 12138 (2017)

12. Prospects of construction and maintenance of skyscrapers in the 21st century [Electronic resource] - Access mode: https://regrazvitie.ru/perspektivy-stroitelstva-i-ekspluatatsiineboskrebov-v-21-veke/ (2018) 